Tropical Journal of Pharmaceutical Research November 2016; 15 (11): 2303-2309

ISSN: $1596-5996$ (print); 1596-9827 (electronic)

(C) Pharmacotherapy Group, Faculty of Pharmacy, University of Benin, Benin City, 300001 Nigeria.

All rights reserved.

Available online at http://www.tjpr.org

Original Research Article

http://dx.doi.org/10.4314/tjpr.v15i11.2

\title{
Preparation and in vitro evaluation of amoxicillin encapsulated in alginate-coated chitosan microparticles
}

\author{
Ebele Onuigbo*, Adaeze Onugwu, Matthew Nwocha, Augustine Odiase and \\ Anthony Attama
}

Department of Pharmaceutics, Faculty of Pharmaceutical Sciences, University of Nigeria, Nsukka, Nigeria, 410001, Enugu State, Nigeria

*For correspondence: Email: ebele.onuigbo@unn.edu.ng; Tel: +234-806-299-5712

\begin{abstract}
Purpose: To optimize and characterize amoxicillin encapsulated in mucoadhesive alginate-coated chitosan microparticles for the treatment of gastric and duodenal ulcers caused by Helicobacter pylori. Methods: Eighteen batches of various ratios of chitosan, sodium alginate and calcium chloride were prepared by ionotropic gelation method. The batches were optimized based on their particle size (PS) and drug encapsulation efficiency (PDEE). Optimized batches were further evaluated for in vitro drug release, bacterial susceptibility and mucoadhesion.

Results: Microparticle size ranged from $0.70 \pm 0.37$ to $5.25 \pm 0.70 \mu \mathrm{m}$. Drug encapsulation efficiency ranged from 95.79 to $97.42 \%$ while maximum drug released after $24 \mathrm{~h}$ was $44.79 \%$ in simulated gastric fluid (SGF). Mucoadhesion reached a maximum of $76 \%$ in simulated intestinal fluid (SIF). Drug release followed Higuchi model of release kinetics while the release exponent, $n$, was $>0.9$ in all the formulations. There was a significant difference between the inhibition zone diameter (IZD) of the optimized formulations and that of a commercial brand of amoxicillin when they were tested against Salmonella typhi and Staphylococcus aureus.

Conclusion: The mucoadhesive amoxicillin microparticles may improve the treatment of gastric ulcer caused by $H$. pylori due to enhanced adhesion of the formulation to the pig's ileum and the increased antibacterial property against Salmonella typhi and Staphylococcus aureus.
\end{abstract}

Keywords: Amoxicillin, Gastric ulcer, Microparticles, Chitosan, Alginate, Encapsulation, Mucoadhesion

Tropical Journal of Pharmaceutical Research is indexed by Science Citation Index (SciSearch), Scopus, International Pharmaceutical Abstract, Chemical Abstracts, Embase, Index Copernicus, EBSCO, African Index Medicus, JournalSeek, Journal Citation Reports/Science Edition, Directory of Open Access Journals (DOAJ), African Journal Online, Bioline International, Open-J-Gate and Pharmacy Abstracts

\section{INTRODUCTION}

Amoxicillin, a semi-synthetic, orally absorbed, broad-spectrum antibiotic is still commonly used in the treatment of gastric and duodenal ulcers caused by $H$. pylori. One reason for incomplete eradication of $H$. pylori is probably the short residence time of amoxicillin in the gastrointestinal tract so that effective antimicrobial concentration cannot be achieved in the gastric mucous layer or epithelial cell surfaces where $H$. pylori resides. Another reason may be the degradation of amoxicillin in the harsh stomach environment [1].

Polymeric drug carriers have played an integral role in the advancement of drug delivery technology offering three major advantages in delivery which are sustained release, targeted delivery and stabilization of the drug [2]. Preferably, the carrier for oral delivery should be mucoadhesive, biodegradable, biocompatible and non-toxic. A suitable approach would be a local application of the drug on to the gastric 
mucosal layer with a concept of mucoadhesion that can adhere on to the bacterium, thus eliminating it completely [3]. Chitosan, the polymer of choice in this research is a linear heteropolymer of $\mathrm{N}$-acetyl-D-glucosamine linked by $\beta-(1-4)$ glycosidic bonds. It is non-toxic, biodegradable, biocompatible and mucoadhesive. Therefore, chitosan microparticles and their derivatives have been applied in biomedical field such as antibacterial agents, gene delivery vectors, carriers for release of protein and drugs [4]. Also, the combination of chitosan and amoxicillin may be synergistic as chitosan exhibits antimicrobial activity [3]. Chitosan microparticles can be formed by a variety of methods including emulsion, ionotropic gelation or reverse micellar methods. The method used here is ionotropic gelation method [5].

Sodium alginate is also a hydrophilic polymer and comprises D-mannuronic (M) and Lguluronic acid $(G)$ residues joined linearly by 1,4glycosidic linkages [6]. Alginate-coated chitosan microparticles protects acid-labile drugs better from degradation in acidic solution $(\mathrm{pH} 1.5)$ than the chitosan microparticles alone. The coating also acts as a barrier from microbial contamination [7]. This research seeks to optimize and characterize amoxicillin encapsulated in mucoadhesive alginate-coated chitosan microparticles for the treatment of gastric and duodenal ulcers. The alginate coat prolongs contact with the intestinal mucosa and thus improve therapeutic response.

\section{EXPERIMENTAL}

\section{Materials}

The following materials were used as procured without further purification: sodium alginate, low molecular weight chitosan, calcium chloride, acetic acid, Tween ${ }^{\circledR} 80$ and sodium sulphate (Sigma Aldrich Co., Germany), distilled water and deionized water (National Commission for Energy Research and Development, University of Nigeria, Nsukka), amoxicillin (donation from Juhel Pharmaceutical Company, Emene, Enugu).

\section{Preparation of microparticles}

Alginate/chitosan microparticles were prepared in a two-step procedure based on ionotropic gelation method. A pre-gelation of polyanionic alginate with calcium chloride followed by dropwise addition of polycationic chitosan crosslinked by sodium sulphate was prepared. Thus in details, a volume of $5 \mathrm{~mL}$ of $2 \%$ w/v chitosan containing $250 \mathrm{mg}$ of amoxicillin was cross-linked with $3.5 \mathrm{ml}$ of $10 \%$ sodium sulphate at a rate of $1 \mathrm{ml} / \mathrm{min}$ under mild agitation (<50 rpm) and continuous sonication (Ultra turrax homogenizer, Silverson, U.K) for $15 \mathrm{~min}$ (room temperature, $\mathrm{pH}$ of 4.7) for the microparticle formation. Thereafter, $1 \mathrm{ml}$ of $0.55 \mathrm{mM}$ calcium chloride solution was dropped for $30 \mathrm{~min}$ under $50 \mathrm{rpm}$ in a beaker containing $5 \mathrm{~mL}$ of $2 \% \mathrm{w} / \mathrm{v}$ sodium alginate solution. The chitosan microparticles were dropped slowly, using a 23-gauge needle, into the alginate solution to achieve alginate coating of the chitosan microparticles. The coated microparticles in suspension were centrifuged at $3500 \mathrm{rpm}$ for $30 \mathrm{~min}$. This was done in eighteen runs.

\section{Stock solutions}

Stock solutions of chitosan, sodium alginate and calcium chloride were prepared. The ratios are shown in Table 1.

Table 1: Experimental design including variables

\begin{tabular}{|c|c|c|c|c|}
\hline $\begin{array}{l}\text { Independent } \\
\text { variables }\end{array}$ & Symbols & $\begin{array}{l}\text { Low } \\
\text { level } \\
(-)\end{array}$ & $\begin{array}{l}\text { Basal } \\
\text { level } \\
\text { (0) }\end{array}$ & $\begin{array}{l}\text { High } \\
\text { level } \\
(+)\end{array}$ \\
\hline $\begin{array}{l}\text { Chitosan } \\
(\mathrm{mg} / \mathrm{ml})\end{array}$ & $A$ & 2.5 & 5 & 7.5 \\
\hline $\begin{array}{l}\text { Sodium } \\
\text { alginate (mg/ } \\
\mathrm{ml})\end{array}$ & B & 2 & 2.5 & 5 \\
\hline $\begin{array}{l}\text { Calcium } \\
\text { chloride (mM) }\end{array}$ & C & 0.55 & 1.0 & 1.8 \\
\hline $\begin{array}{l}\text { Dependent } \\
\text { variable }\end{array}$ & \multicolumn{2}{|c|}{ Units } & \multicolumn{2}{|c|}{ Constraints } \\
\hline $\begin{array}{l}\text { Particle size (PS } \\
\text { Encapsulation } \\
\text { efficiency (EE) }\end{array}$ & $\begin{array}{l}\mu \mathrm{m} \\
\%\end{array}$ & & \multicolumn{2}{|c|}{$>90$} \\
\hline
\end{tabular}

\section{Particle size determination}

The residue of the centrifuged sample was washed twice with distilled water and used for the particle size determination. A thin smear was made on a glass slide and viewed with $\mathrm{Hund} \circledast$ binocular microscope (Helmut Hund $\mathrm{GmbH}$, Weltzlar, Germany) attached to a Motic image analyser (Moticam, Xiamen, China) at a magnification of $x 40$. Three different fields of view were captured for each sample and the average taken.

\section{Percent drug encapsulation efficiency (PDEE)}

For quantitative determination of amoxicillin loading, samples were centrifuged and then the absorbance of the solutions in the tubes was measured at $267.5 \mathrm{~nm}$ wavelength using a UV/VIS spectrophotometer ((Spectrumlab 752S, 
USA). The amount of amoxicillin associated with the microparticles was calculated indirectly by the difference between the initial amount of amoxicillin added to the chitosan and the amount measured in the supernatant. Eq 1 was used to determine drug encapsulation efficiency (PDEE).

PDEE $(\%)=\{(\mathrm{At}-\mathrm{As}) / \mathrm{At}\} 100$

where $A t$ and $A s$ are the total amount of amoxicillin and amount of amoxicillin in the supernatant, respectively.

\section{Optimization studies}

The optimization process was done using the constraints imposed by the investigator seen in Table 1. Three optimal runs based on the constraints were selected for further evaluation.

\section{Mucoadhesion}

The mucus surface of a freshly excised pig's ileum was rinsed with normal saline. The tissue was pinned to a polythene support on a wooden board inclined at an angle of $60^{\circ}$ with the aid of board pins and a beaker was placed under the base of the inclined plane to collect the microparticles as they get detached from the tissue. A $500 \mathrm{mg}$ weight of the microparticles was placed on the trough of the mucus surface and allowed to hydrate for $15 \mathrm{~min}$. A $100 \mathrm{ml}$ of SIF was allowed to flow over the tissue at the rate of $40 \mathrm{drops} / \mathrm{min}$. The wet microparticles detached was blotted dry with a filter paper and weighed. The weight of the microparticles calculated as a percentage of the original weight was used as a measure of mucoadhesion. The experiment was repeated using SGF.

\section{In vitro release studies}

The dissolution medium consisted of $250 \mathrm{~mL}$ of freshly prepared SGF and SIF maintained at $37 \pm$ $1{ }^{\circ} \mathrm{C}$ using a heater/magnetic stirrer. The polycarbonate dialysis membrane used was pretreated by soaking it in the dissolution media for $24 \mathrm{~h}$. For the study, $0.5 \mathrm{~g}$ of the formulated alginate-coated chitosan microparticles was placed in the dialysis membrane containing $5 \mathrm{~mL}$ of each of the dissolution medium, securely tied to a thermo-resistant thread and then immersed in the dissolution medium under agitation provided by the magnetic stirrer at $100 \mathrm{rpm}$. At predetermined time intervals, $5 \mathrm{~mL}$ portions of the dissolution medium were withdrawn, filtered and analysed spectrophotometrically (UV/VIS spectrophotometer (Spectrumlab 752S)) at 267.5 $\mathrm{nm}$. For each sample withdrawn, an equivalent volume $(5 \mathrm{~mL})$ of phosphate buffer maintained at the same temperature was added to the contents of the dissolution medium to maintain sink conditions throughout the release period. The amount of drug released at each time interval was determined with reference to the standard Beer's plot for amoxicillin in phosphate buffer [8].

\section{Kinetic analysis of drug release}

The in vitro drug release kinetic data were tested with the following mathematical models; zeroorder equation, first-order equation, Higuchi square-root equation and Korsmeyer-Peppas model to find the equation with the best fit.

\section{Susceptibility studies on clinical isolates}

Molten nutrient agar $(15 \mathrm{~mL})$ was inoculated with $0.1 \mathrm{ml}$ of Escherichia coli broth culture. It was mixed thoroughly, poured into Petri dishes and rotated to ensure even distribution of the organism. The agar plates were allowed to set and a sterile cork-borer ( $5 \mathrm{~mm}$ diameter) was used to cut three cups in the agar medium plate. The three different optimized microparticles were prepared and used as follows: 3 drops each of the optimized formulations were added into the different holes in each of the plates using sterile Pasteur pipettes. The plates were allowed to stand at room temperature for $15 \mathrm{~min}$ to enable the samples diffuse into the medium before incubating at $37^{\circ} \mathrm{C}$ for $24 \mathrm{~h}$. The inhibition zone diameters were carefully measured and recorded. The procedure above was repeated for broth cultures of Salmonella typhi and Staphylococcus aureus.

\section{Statistical analysis}

The results of the susceptibility test were expressed as mean \pm standard deviation (SD), and were analyzed by Students t-test using Microsoft Excel 2010 was used. $P<0.05$ was considered as statistically significant.

\section{RESULTS}

\section{Particle size}

The technique used for the preparation of the microparticles was ionotropic gelation. The photomicrographs of the vesicles were spherical and polydisperse with sizes ranging from $0.70 \pm$ 0.37 to $5.25 \pm 0.70 \mu \mathrm{m}$ as seen in Table 2 . 
Table 2: Concentrations of independent variables and the responses of dependent variables

\begin{tabular}{lcccc}
\hline $\begin{array}{l}\text { Chitosan } \mathbf{( m g /} \\
\mathbf{m l})\end{array}$ & $\begin{array}{c}\text { Sodium alginate } \\
(\mathbf{m g} / \mathbf{m l})\end{array}$ & $\begin{array}{c}\text { Calcium } \\
\text { chloride } \\
(\mathbf{m M} \mathbf{)}\end{array}$ & Particle size $(\boldsymbol{\mu m})$ & $\begin{array}{c}\text { Encapsulation } \\
\text { efficiency } \mathbf{\%})\end{array}$ \\
\hline 5 & 5 & 1.0 & $5.25 \pm 0.70$ & 97.02 \\
5 & 2.5 & 1.8 & $3.26 \pm 0.92$ & 96.39 \\
7.5 & 5 & 0.55 & $1.1 \pm 0.62$ & 96.29 \\
7.5 & 7.5 & 1.0 & $1.33 \pm 0.22$ & 96.43 \\
2.5 & 7.5 & 1.0 & $1.30 \pm 0.21$ & 96.91 \\
2.5 & 5 & 1.8 & $0.98 \pm 0.62$ & 96.21 \\
7.5 & 5 & 1.8 & $2.58 \pm 1.02$ & 97.1 \\
5 & 2.5 & 0.55 & $2.73 \pm 0.38$ & 97.28 \\
5 & 7.5 & 1.8 & $2.82 \pm 0.74$ & 96.98 \\
2.5 & 2.5 & 1.0 & $0.70 \pm 0.36$ & 97.18 \\
7.5 & 2.5 & 1.0 & $3.78 \pm 1.64$ & 96.71 \\
2.5 & 5 & 0.55 & $2.48 \pm 1.49$ & 96.39 \\
5 & 7.5 & 0.55 & $4.20 \pm 0.92$ & 97.42 \\
7.5 & 7.5 & 1.8 & $3.97 \pm 1.04$ & 96.66 \\
2.5 & 2.5 & 0.55 & $3.50 \pm 0.22$ & 97.1 \\
5 & 5 & 0.55 & $1.75 \pm 0.42$ & 97.23 \\
5 & 5 & 1.8 & $2.80 \pm 1.40$ & 96.7 \\
7.5 & 5 & 1.0 & $1.45 \pm 0.44$ & 95.79 \\
\hline
\end{tabular}

Percent drug encapsulation efficiency (PDEE)

Eighteen microparticulate formulations were evaluated for drug encapsulation efficiency and the results of the PDEE is shown in Table 2. The range was between $95.79-97.42 \%$. This was above the minimum constraint on PDEE.

\section{Optimization of the batches}

Based on the constraints imposed on particle size and percent drug encapsulation efficiency, three formulations were selected and evaluated. The results are shown in Table 3.

Table 3: Optimized batches and their correspondent dependent variables

\begin{tabular}{|c|c|c|c|}
\hline $\begin{array}{l}\text { Formulation } \\
\text { code }\end{array}$ & $\begin{array}{l}\text { Ratio of } \\
C: A: C^{a}\end{array}$ & $\begin{array}{l}\text { PDEE } \\
(\%)\end{array}$ & $\begin{array}{c}\text { PS } \\
(\mu \mathrm{m})^{\mathrm{c}}\end{array}$ \\
\hline $\mathrm{F} 1$ & $7.5: 2.5: 0.55$ & 96.29 & $\begin{array}{l}1.1 \pm \\
0.62\end{array}$ \\
\hline F2 & 2:2.5:1.8 & 96.29 & $\begin{array}{c}0.98 \pm \\
0.62\end{array}$ \\
\hline F3 & $2: 2: 1.0$ & 97.18 & $\begin{array}{c}0.70 \pm \\
0.36\end{array}$ \\
\hline
\end{tabular}

Key: ${ }^{a} \mathrm{C}: \mathrm{A}: \mathrm{C}=$ chitosan:alginate:calcium chloride; ${ }^{\mathrm{b}} \mathrm{PDEE}=$ percent drug encapsulation efficiency; ${ }^{\mathrm{C}} \mathrm{PS}=$ particle size

\section{Determination of mucoadhesion of microparticles on hog everted tissue}

The mucoadhesion of the microparticles in SIF $(\mathrm{pH}$ 7.2) and SGF (pH 1.2) are presented in Table 4. The result showed higher mucoadhesion in SIF. F1 had the highest mucoadhesion of $76 \%$ to the everted hog tissue while $\mathrm{F} 2$ and $\mathrm{F} 3$ were $60 \%$ which was equally high. In SGF, the mucoadhesion was very low with $\mathrm{F} 1, \mathrm{~F} 2$ and $\mathrm{F} 3$ having mucoadhesion from $32-36 \%$.

Table 4: Mucoadhesion of the microparticles ex vivo in SIF and SGF

\begin{tabular}{lcc}
\hline $\begin{array}{l}\text { Formulation } \\
\text { code }\end{array}$ & $\begin{array}{c}\text { Mucoadhesion } \\
\text { in SIF (\%) }\end{array}$ & $\begin{array}{c}\text { Mucoadhesion } \\
\text { in SGF (\%) }\end{array}$ \\
\hline F1 & 76 & 36 \\
F2 & 60 & 32 \\
F3 & 60 & 32 \\
\hline
\end{tabular}

\section{In vitro drug release}

The release profiles of different formulations (F1 to F3) are shown in Figures $1 a$ and $b$. In SIF for a maximum of $24 \mathrm{~h}$, a cumulative of $21.28 \%$, $30.89 \%$ and $38.85 \%$ of amoxicillin were released from F1, F2 and F3 respectively while $28.28 \%, 37.25 \%$ and $44.59 \%$ of amoxicillin were released from F1, F2 and F3 respectively in SGF.

\section{Drug release kinetics}

It can be seen from Tables 5 and 6 that the coefficient of determination $\left(r^{2}\right)$ is highest in the Higuchi model in both SIF and SGF and in all the formulations. The highest was 0.94 and this means that $94 \%$ variability in the response will be explained by the model. The drug release data was fitted to the well-known exponential equation (Korsmeyer-Peppas equation) which is often used to describe the drug release behavior from polymeric systems. From Table 5, F1 to F3 had $n$-values higher than 1 in SIF while $\mathrm{F} 1$ to F3 had values between 0.94 and 1.09 in SGF. 


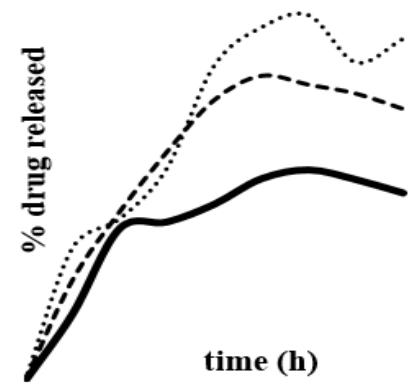

(a)

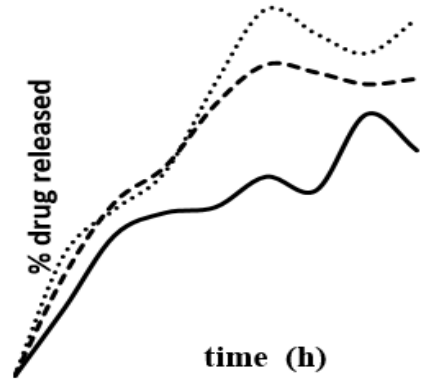

(b)

Figure 1: Release profile of coated chitosan microparticles in (a) SIF and (b) SGF. Key: F1 = dotted line; F2 = dashed line; F3 = unbroken line

Table 5: Kinetic parameters of amoxicillin encapsulated in alginate-coated chitosan microparticles in SIF and SGF

\begin{tabular}{lcccccccc}
\hline $\begin{array}{l}\text { Formulation } \\
\text { code }\end{array}$ & \multicolumn{2}{c}{ Zero order } & \multicolumn{2}{c}{ First order } & \multicolumn{2}{c}{ Higuchi Model } & \multicolumn{2}{c}{$\begin{array}{c}\text { Korsemeyer- } \\
\text { Peppas }\end{array}$} \\
\cline { 2 - 9 } & $r^{2}$ & $K_{0}$ & $r^{2}$ & $K_{1}$ & $r^{2}$ & $K_{H}$ & $r^{2}$ & $n$ \\
\hline SIF & & & & & & & & \\
F1 & 0.77 & 0.87 & 0.75 & -0.004 & 0.91 & 4.66 & 0.82 & 1.32 \\
F2 & 0.80 & 1.49 & 0.74 & -0.006 & 0.90 & 7.18 & 0.87 & 1.38 \\
F3 & 0.85 & 1.81 & 0.80 & -0.008 & 0.93 & 8.69 & 0.91 & 1.41 \\
SGF & & & & & & & & \\
F1 & 0.88 & 0.87 & 0.79 & -0.004 & 0.92 & 4.99 & 0.85 & 0.94 \\
F2 & 0.80 & 1.49 & 0.82 & -0.008 & 0.94 & 8.54 & 0.87 & 1.06 \\
F3 & 0.85 & 1.81 & 0.86 & -0.010 & 0.92 & 9.95 & 0.87 & 1.09 \\
\hline
\end{tabular}

Susceptibility of microorganisms to alginatecoated amoxicillin-loaded microparticles

Figure 2 shows that Staphylococcus aureus was most susceptible to the three optimized formulations as well as the marketed amoxicillin tablet. The highest IZD of $53.66 \pm 1.53 \mathrm{~mm}$ was produced by F1 against Staphylococcus aureus.

When the formulations were compared with the commercial amoxicillin, there was no significant difference at $p<0.05$ in the inhibition zone

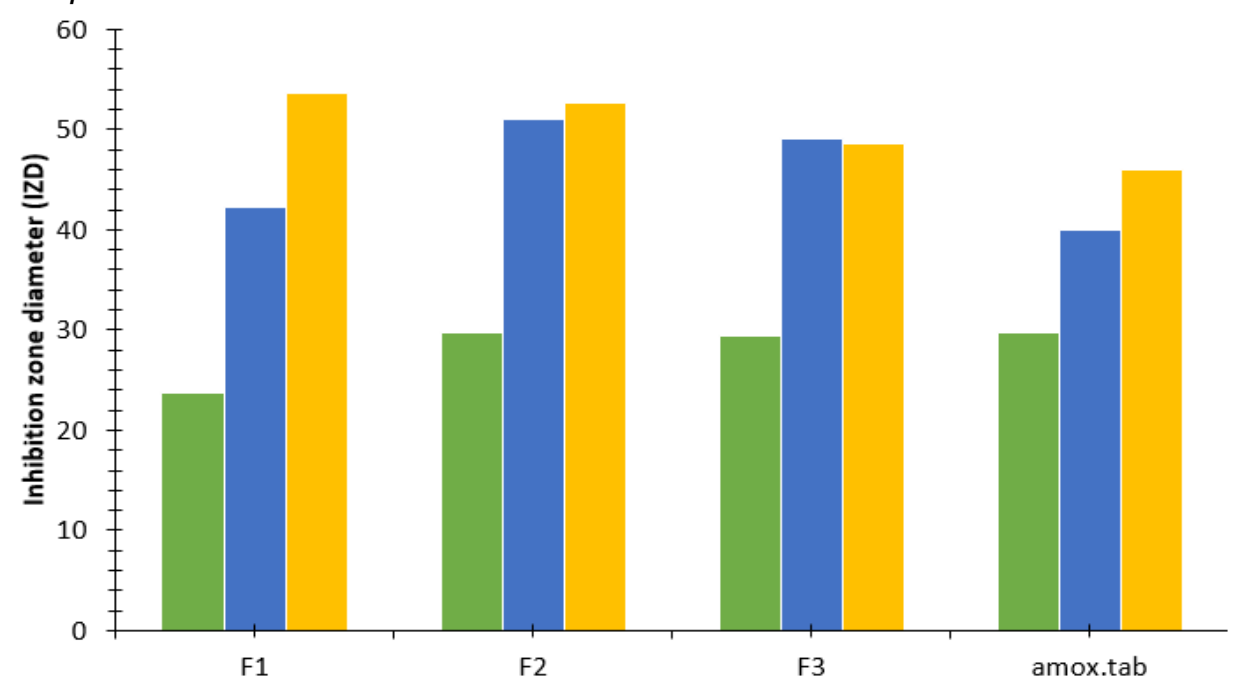

Figure 2: Inhibition zone diameters of the optimized batches against the isolates. Colour code: Green = E.coli; blue $=S$. typhi; orange $=S$. aureus diameters against $E$. coli. There were some significant differences between F2, F3 and the commercial amoxicillin against Salmonella typhi. There were also significant differences between F1, F2 and the commercial amoxicillin against Staphylococcus aureus. There were significant differences in the inhibitions of formulations $F 1$, F2 and F3 on S. typhi in this order: F2 > F3 >F1. There was no significant difference in the activities of the three formulations on $E$. coli as seen in Table 6. 
Table 6: Statistical data on antibacterial activity of the formulation on clinical isolates

\begin{tabular}{lccc}
\hline Formulation & E. coli & Salmonella typhi & S. aureus. \\
\hline F1 and Standard & 0.074 & 0.29 & $0.000021^{*}$ \\
F2 and Standard & 1 & $0.00022^{*}$ & $0.0065^{*}$ \\
F3 and Standard & 0.9 & $0.0023^{*}$ & 0.374 \\
F1 and F2 & 0.074 & $0.00167^{*}$ & 0.24 \\
F1 and F3 & 0.345 & $0.01^{*}$ & 0.14 \\
F2 and F3 & 0.900 & $0.03^{*}$ & 0.32 \\
\hline
\end{tabular}

*Significant difference at $p<0.05$

\section{DISCUSSION}

The particles ranged from 0.70 to $5.25 \mu \mathrm{m}$. The distribution of the sizes was varied. There was no significant correlation between the different ratios of the independent variables and particle size though there was an occurrence of low concentration of chitosan and small sizes of the microparticles. The size range is appropriate for oral delivery and uptake.

The high encapsulation of amoxicillin drug shows a strong affinity of the drug for the biopolymer and a good absorption enhancing effect of the microparticles [9]. A drug associates with chitosan through hydrophobic interactions or electrostatic interactions or hydrogen bonding. The coating of alginate which is hydrophilic would also greatly increase circulation time of the microparticles in the system [9]. Alginate coating would also prevent rapid degradation of the amoxicillin in the gastric fluid if delivered orally. It is essential in drug delivery to determine the encapsulation efficiency of a carrier because its efficacy depends strongly on it [10]. Adhesive properties of mucoadhesive polymers are generally affected by their swelling behavior. Mucoadhesive microparticles take up water from the underlying mucosal tissue by absorption, swelling, capillary effects and uncoiling of polymer chains leading to considerably stronger adhesion [11]. The alginate-coated chitosan microparticles had a strong adhesion to the ileum in SIF but was eroded in the presence of SGF due to poor hydration and swelling of the polymer in the acidic environment leading to low adhesion. There may also be poor interaction of the alginate with the sialic acid and other anionic groups present on the mucin [3].

The slow release of amoxicillin from the microparticles may be due to high viscosity of the alginate gels or strong affinity of the drug to the chitosan particles which resulted in hindered migration of amoxicillin molecules in the dissolution medium. Alginate gels have also been utilized to form a matrix in which depots releasing small drugs can be incorporated, for example, amoxicillin-loaded Chitosan/poly( $\gamma$ glutamic acid) nanoparticles have been incorporated into alginate/calcium ions hydrogels for effective treatment of Helicobacter pylori infection. The alginate gel outer layer protected the amoxicillin-loaded nanoparticles in the gastric environment, and facilitated amoxicillin interactions specifically with intercellular spaces, which is the infection site of $H$. pylori [12]. When a microparticle is brought into contact with a liquid medium, the solvent diffuses into the polymer, causing it to swell. $\mathrm{pH}$ and cross-linking also control the rate of swelling. Diffusion occurs which involves migration of water into preexisting or dynamically formed spaces between hydrogel chains [12]. The $n$-values of the diffusion of amoxicillin through the alginatecoated polymer was between 0.94 and 1.09 showing mostly non-fickian diffusion mechanism meaning that the diffusion and relaxation rates were comparable. The result of the sensitivity studies which was done under similar conditions showed that there was no reduction in potency or stability of the amoxicillin encapsulated in alginate-coated chitosan microparticles by ionotropic gelation method.

\section{CONCLUSION}

Alginate-coated chitosan microparticles hold good prospects for amoxicillin drug delivery for gastric ulcer therapy. It is biodegradable, biocompatible and mucoadhesive. The ionotropic gelation technique produced particles with suitable mean size and high encapsulation efficiency. Drug release is sustained and mucoadhesion high in simulated gastric fluid.

\section{DECLARATIONS}

\section{Acknowledgement}

The authors wish to thank Juhel Pharmaceutical Company, Enugu, Nigeria for the gift of amoxicillin drug and also International Foundation for Science (IFS) for financial support.

\section{Conflict of Interest}

No conflict of interest associated with this work. 


\section{Contribution of Authors}

The authors declare that this work was done by the authors named in this article and all liabilities pertaining to claims relating to the content of this article will be borne by them.

\section{REFERENCES}

1. Raval J, Patel J, Patel M. Formulation and in vitro characterization of spray-dried microspheres of amoxicillin. Acta Pharm 2010; 60: 455-465.

2. Liechty WB, Kryscio DR, Slaughter BV, Peppas NA. Polymers for drug delivery systems. Annu Rev Chem Biomol Eng 2010; 1: 149-173.

3. Arora S, Budhiraja RD. Chitosan-alginate microcapsules of amoxicillin for gastric stability and mucoadhesion. $J$ Adv Pharm Technol Res 2012; 3(1): 68-74.

4. Nguyen $A D$, Nguyen $T N H$, Dang THV, Nguyen TLP, Nguyen TNQ, Dinh $M H$, Le Van $H$. Chitosan nanoparticle as a novel delivery system for $A / H 1 N 1$ influenza vaccine. Safe property and immunogenicity in mice. World Acad Sci Engineer and Technol 2011; 60 : 1839 - 1846

5. Sarmento $B$, Ferreira $D$, Veiga $F$, Ribeiro $A$. Characterization of insulin-loaded alginate nanoparticles produced by ionotropic pre-gelation through DSC and FTIR studies. Carbohydr Polym 2006; 66: 1-7.
6. Gazori $T$, Khoshayand MR, Azizi E, Yazdizade $P$, Nomani A, Haririan I. Evaluation of Alginate/Chitosan nanoparticles as antisense delivery vector: Formulation, optimization and in vitro characterization. Carbohyd Polym 2009; 77: 599-606.

7. Borges O, Borchard G, Verhoef J. Preparation of coated nanoparticles for a new mucosal vaccine delivery system. Inter J Pharm 2005; 299: 155-166.

8. Umeyor EC, Kenechukwu FC, Ogbonna JD, Chime AS, Attama AA. Preparation of novel solid lipid microparticles loaded with gentamicin and its evaluation in vitro and in vivo. J Microencapsul 2012; 29(3): 296307.

9. Tiyaboonchai W. Chitosan nanoparticles: A promising system for Drug delivery. Naresuan Univ J 2003; 11(3): 51-66.

10. Zhao $K$, Zhang $Y$, Zhang $X$. Preparation and efficacy of Newcastle disease virus DNA vaccine encapsulated in chitosan nanoparticles. Int J Nanomed 2014; 19.2147/S54226.

11. Hou J, Gao L, Meng F, Cui Y. Mucoadhesive microparticles for gastroretentive delivery. Preparation, biodistribution and targeting evaluation. Mar Drugs 2014; 12(12): 5764-5787.

12. Chang $\mathrm{CH}$, Liu YH, Yeh CC, Chen YC, Chiou SF, Hsu YM, Chen YS, Wang CC. Nanoparticles incorporated in $\mathrm{pH}$-sensitive hydrogels as amoxicillin delivery for eradication of Helicobacter pylori. Biomacromol 2010; 11: 133-142. 